\title{
Evaluation Items for Community-Based Health Care Focusing on Social Aspects: A Literature Review
}

\author{
Junko Imaiso \\ Kansai University of Social Welfare, Shinden, Ako-shi, Hyogo-Pref., Japan \\ Email: imaiso@kusw.ac.jp
}

How to cite this paper: Imaiso, J. (2021) Evaluation Items for Community-Based Health Care Focusing on Social Aspects: A Literature Review. Health, 13, 1488-1495. https://doi.org/10.4236/health.2021.1312106

Received: May 31, 2021

Accepted: December 20, 2021

Published: December 23, 2021

Copyright $\odot 2021$ by author(s) and Scientific Research Publishing Inc. This work is licensed under the Creative Commons Attribution-NonCommercial International License (CC BY-NC 4.0). http://creativecommons.org/licenses/by-nc/4.0/ (c) (i) (8) Open Access

\begin{abstract}
The progressive aging of society has become a global concern, and is expected to lead to the development of effective, sustainable, person-centered, integrated community-based care systems. However, there is insufficient evidence regarding effective integrated community-based care. In particular, few studies have focused on social aspects of the community environment related to elderly health. This study aimed to consider social aspects as evaluation items, focusing particularly on social determinants from the perspective of community-dwelling people, to explore truly effective integrated community-based care to improve elderly health. The definition of social determinants means social cohesion in social and community contexts. A literature review of English articles published in peer-reviewed journals up to October 2019 was conducted using PubMed, MEDLINE, and CINAHL with the following search terms: "social cohesion," "elderly health," "mental health" and "community." Identified articles were screened based on title and abstract, and selected articles were subjected to full-text assessment and critical review. All references cited in the selected articles were also reviewed. The following inclusion criteria were used: 1) studies targeting community-dwelling elderly people or community-dwelling people including elderly people as participants; 2) studies with clear descriptions of social factors in the Methods section; and 3) studies with clear descriptions of health-related items in the Methods section. From the 21 articles analyzed, of which 9 articles defined social determinants as social cohesion in social and community context, 37 items were extracted as social aspects at the community level that reflect the perspective of residents. These items can be developed as evaluation items for community-based health care outcomes through consensus among community health care providers and further investigation.
\end{abstract}




\section{Keywords}

Social Determinants, Community Environment, Evaluation Items, Community-Based, Primary Health Care

\section{Introduction}

The progressive aging of society has become a global health issue, and the need to create a healthy longevity society is expected to grow. As the possibility of requiring care increases with age, an effective and seamless community-based care system needs to be developed for elderly populations, which would also promote the health of other age groups such as children or younger adults in the community. Regional primary health care will become more important in the future.

Various intervention studies have been conducted in community-dwelling elderly people (aged $\geq 60$ or $\geq 65$ years) to show the effectiveness of integrated community-based care in Western countries such as the Netherlands and Canada [1], but evidence on a global scale is still lacking. To create an effective, sustainable, person-centered care system that also considers community characteristics, the effectiveness of community-based care must be showed globally from the perspective of community-dwelling people via longitudinal studies. A previous literature review [2] revealed the following 3 aspects of healthy living in community-dwelling elderly people as outcomes of effective integrated community-based care: physical and social functioning, physical and mental health, and quality of life (QOL). Compared to physical and mental health, fewer studies have focused on social health. According to the World Health Organization (WHO) [3], social determinants of health $(\mathrm{SDH})$ are non-medical factors that influence health outcomes, and they are the conditions in which people are born, grow, work, live, and age, and the wider set of forces and systems shaping the conditions of daily life. These forces and systems include economic policies and systems, development agendas, social norms, social policies, and political systems. Phillips et al. [4] reported that SDH, which reportedly accounts for 30-55\% of health outcomes, has received considerable attention globally given its tremendous influence in shaping health status, QOL, and health outcomes. Social determinants should be more focused on the research on outcomes of community-based care for the elderly to consider the effectiveness of community-based care systems.

In the field of gerontology, communities must be studied as something that strongly influences the well-being and QOL of elderly people [5]. Elderly people spend more time at home, rely more on local resources to achieve a better QOL, and are more emotionally attached to their community compared to younger adults [6], and their health is affected by the residential area they live in. When the health of community-dwelling elderly people is of particular interest, the focus should be placed on social determinants related to the community, as well as individual health-related factors. It is thus important that elderly health care 
providers understand, and be aware of, their community environment. Community characteristics based on differences in community environments (e.g., urban versus rural) are factors that influence elderly health [7]. For example, cross-sectional studies in the United States, Thailand, and Taiwan have reported significant differences in social function (e.g., social participation) and mental health of elderly people living in urban and rural areas [8] [9] [10] [11]. Moreover, understanding their community environment may help health care providers perceive the characteristics of their community, and this, in turn, may lead to the development of an effective, integrated, community-based care system.

This study aimed to consider social aspects as evaluation items, focusing particularly on social determinants from the perspective of community-dwelling people, to promote an effective, integrated, community-based care system for the health of community-dwelling elderly people through a literature review.

\section{Methods}

\subsection{Literature Search}

There currently is no clear definition of social determinants in research. According to a previous study [12], social cohesion is a key term related to sustainable and resilient systems. When considering the development of an effective, sustainable, integrated community-based care system that takes into account community characteristics, social cohesion may be an important social factor associated with elderly health [13]. Therefore, in the present study, the definition of social determinants means social cohesion in social and community contexts, and social cohesion was set up as one of the search key terms.

A literature search was performed using PubMed, MEDLINE, and CINAHL for English articles published in peer-reviewed journals up to October 2019 with the following search terms: "social cohesion," "elderly health," "mental health," and "community." Identified articles were screened based on title and abstract, and selected articles were subjected to full-text assessment and critical review. In addition, all references cited in the selected articles were reviewed. The following inclusion criteria were used: 1) studies targeting community-dwelling elderly people or community-dwelling people including elderly people as participants; 2) studies with clear descriptions of social factors in the Methods section; and 3) studies with clear descriptions of health-related items, such as physical health, chronic conditions, health behaviors, depression, mental well-being, and QOL, in the Methods section.

\subsection{Extraction of Social Items}

To consider social aspects as evaluation items for community-based care, all items related to social aspects (except economic aspects) were extracted from the Methods sections of the identified articles. Duplicate items were omitted, and all extracted items were then ordered by content level, i.e., as individual-level and community-level contents. Individual-level items were omitted if they focused 
on how participants felt living in their community, their family network, or family relations. Items related to how participants perceived their community (i.e., community-level items) were retained as evaluation items for community-based care.

\section{Results}

In total, 118 articles were identified from the search. After excluding 78 articles based on title and abstract, 40 were selected, of which 11 met the inclusion criteria. 14 references cited in the selected articles were also considered through full articles. Four of these articles were omitted based on the inclusion criteria in the present study, resulting in the addition of 10 articles. Ultimately, a total of 21 articles were examined in the present study (Figure 1), of which 9 defined social determinants as social cohesion in social and community context, neighborhood social cohesion (Table 1).

\section{Extracted social items at the community-level}

From the 21 articles analyzed, a total of 233 items such as community participation, sense of belonging, social support, trust, reciprocity, community social environment, and social network density, were extracted. 156 duplicate items were omitted, and 77 were ordered by content.

40 of these were related to the feelings of individuals living in the community (individual-level), and 35 were items related to contents perceived by each individual about their community (community-level). The remaining two items were included in both individual-level and community-level items. The 37 items were determined to represent social aspects at the community level (Table 2).

Table 1. List of nine articles defined social determinants as social cohesion in social and community context.

\begin{tabular}{|c|c|c|}
\hline Authors & Title & Citation \\
\hline Wen M., Cagney K. A., \& Christakis N. A. & $\begin{array}{l}\text { Effect of specific aspects of community social environment on the } \\
\text { mortality of individuals diagnosed with serious illness. }\end{array}$ & $\begin{array}{l}\text { Social Sciences \& Medicine, 61, } \\
1119-1134,2005 .\end{array}$ \\
\hline $\begin{array}{l}\text { Gale, C.R.., Dennison, E.M., Cooper, C. } \\
\text { and Sayer, A.A. }\end{array}$ & $\begin{array}{l}\text { Neigbourhood environment and positive mental health in older people: } \\
\text { The Hertfordshire cohort study. }\end{array}$ & $\begin{array}{l}\text { Health and Place, } 17,867-874 \text {, } \\
2011 .\end{array}$ \\
\hline $\begin{array}{l}\text { Chen, W., Okumiya, K., Wada, T., } \\
\text { Sakamoto, R., Imai, H., Ishimoto, Y., et al. }\end{array}$ & Social cohesion and health in old age: a study in southern Taiwan. & $\begin{array}{l}\text { International Psychogeriatrics, } \\
27,1903-1911,2015 .\end{array}$ \\
\hline Tang, F., Xu, L., Chi, I. and Dong, X. & $\begin{array}{l}\text { Health in the neighborhood and household contexts among older } \\
\text { Chinese Americans. }\end{array}$ & $\begin{array}{l}\text { Journal of Aging and Health, } \\
29,1388-1409,2017 .\end{array}$ \\
\hline $\begin{array}{l}\text { Park, N.S., Jang, Y., Lee, B.S. and } \\
\text { Chiriboga, D.A. }\end{array}$ & $\begin{array}{l}\text { The relation between living alone and depressive symptoms in older } \\
\text { Korean Americans: do feeling of loneliness mediate? }\end{array}$ & $\begin{array}{l}\text { Aging \&. Mental Health, 21, } \\
\text { 304-312, } 2017 .\end{array}$ \\
\hline An, S. and Jang, Y. & $\begin{array}{l}\text { The role of social capital in the relationship between physical constraint } \\
\text { and mental distress in older adults: a latent interaction model. }\end{array}$ & $\begin{array}{l}\text { Aging \& Mental Health, 22, } \\
245-249,2018 .\end{array}$ \\
\hline $\begin{array}{l}\text { Guo, M., Steinberg, N.S., Dong, X. and } \\
\text { Tiwari, A. }\end{array}$ & $\begin{array}{l}\text { A cross-sectional study of coping resources and mental health of } \\
\text { Chinese older adults in the United States. }\end{array}$ & $\begin{array}{l}\text { Aging \& Mental Health, 22, } \\
1448-1455,2018 .\end{array}$ \\
\hline $\begin{array}{l}\text { Honjo, K., Tani, Y., Saito, M., Sasaki, Y., } \\
\text { Kondo, K., Kawachi, I., et al. }\end{array}$ & $\begin{array}{l}\text { Living alone or with others and depressive symptoms, and effect } \\
\text { modification by residential social cohesion among older adults in } \\
\text { Japan: The JAGES longitudinal study. }\end{array}$ & $\begin{array}{l}\text { Journal of Epidemiology, 28, } \\
315-322,2018 \text {. }\end{array}$ \\
\hline Kim, H.H. and Toum, Y. & $\begin{array}{l}\text { Exploring the contingent associations between functional limitations } \\
\text { and depressive symptoms across residential context: a multilevel panel } \\
\text { data analysis. }\end{array}$ & $\begin{array}{l}\text { Aging \& Mental Health, 24, } \\
92-102,2018 .\end{array}$ \\
\hline
\end{tabular}




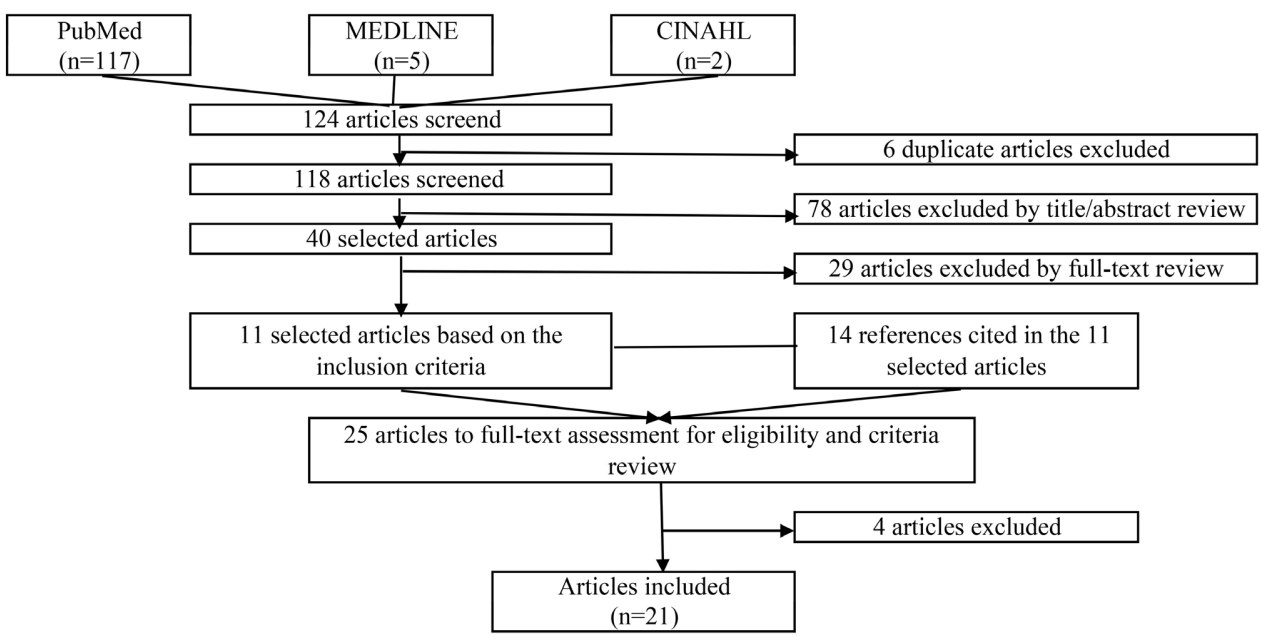

Figure 1. Flowchart of literature search in 2019.

Table 2. Community-level items focused on social aspects extracted from 21 articles.

Items

People in this neighborhood can be trusted.

People around here are willing to help their neighbors.

People in this neighborhood do not share the same values.

People are happy with my neighborhood in the area.

This is a close-knit neighborhood.

People in the neighborhood take advantage of others.

People in the neighborhood keep their word.

People in the neighborhood succeed by stepping on others.

People in the neighborhood are honest.

This is a neighborhood where neighbors look out for each other.

In the neighborhood, the same strong ties that bring benefits to members of a group commonly enable them to bar others from accessing the benefits.

People want to continue to live in this neighbourhood until the end of their lives.

People believe their neighbors would help in case of emergency.

People in the neighborhood participate in activities.

People in this neighborhood have parties or other get-togethers where other people in the neighborhood are invited.

By working together, people in my neighborhood can influence decisions that affect my neighborhood.

People in the neighborhood solve problems.

People encourage others to get involved with a group that is trying to make a difference in the neighborhood.

The success of business initiatives by members of the neighborhood is prevented under certain circumstances.

The neighborhood has downward leveling norms that operate to keep members of a down-trodden group in place. 


\section{Continued}

People in the neighborhood have an adequate level of literacy.

It is easy for people to access social support related to medical treatment or health in the neighborhood.

The health care system for the neighbors is well-established.

People in this neighborhood generally don't get along with each other.

People in this neighborhood visit each other's homes or interact on the street.

People in the neighborhood chat and greet.

People in the neighborhood care for each other.

People in the neighborhood provide assistance.

People in the neighborhood talk in distress.

Many people in the neighborhood are afraid to go out at night.

There are places in this area where everyone knows that "trouble" is expected.

You're taking a big risk if you walk in this area alone after dark.

You can count on adults in this neighborhood to ensure that children are safe and don't get in trouble.

People in the neighborhood would intervene if a fight broke out in front of their house.

The community has residential stability.

People in the neighborhood maintain public hygiene.

In the neighborhood, one can get supplies on credit at the corner store, and children play freely in the streets under the watchful eyes of other adults.

\section{Discussion}

The decline of global population growth is expected to continue as elderly populations increase and birth rates decline. Depopulation of urban areas is also expected to change urban and rural community environments. In Japan, more people are moving to rural areas since the outbreak of COVID-19 in 2019. Understanding the community environment related to population health from the perspective of social determinants may become more important for health care providers. In this context, there is a need to consider evaluation items for community-based care focusing on social determinants to develop effective, sustainable, person-centered, community-based care which considers community characteristics to promote elderly health via longitudinal studies.

In the present study, we first conducted a literature review to identify community-level items to consider as evaluation items focused on social cohesion. From the 21 articles analyzed in this study, 37 items were extracted as community-level social determinants. These items reflected the viewpoint of community-dwelling people, as the studies described in the articles were conducted in community-dwelling people, including elderly residents. Developing these items to evaluate community-based health care outcomes through consensus among community health care providers and further investigation will be important.

The goal of constructing an effective community-based care system is to 
maintain or promote the health of not only elderly people but also all members of the community. Perceiving the community environment in a way that maintains and promotes the social function of the elderly, such as social participation, will lead not only to the health of individuals but also to the community. A previous study suggested the need to take social cohesion into account to better comprehend the connections and independencies between the individual, the community, and institutions [12]. In the future, items focused on social aspects will need to be considered through consensus building among health care providers and medical and welfare facilities related to community-based care, not only for the elderly but also for other age groups. Improving population health also requires addressing the non-behavioral determinants of health, i.e., social, health care, and environmental factors [14]. Focusing on social aspects in developing effective community-based care is expected to promote the health of community-dwelling people, which in return will lead to better community development through a truly effective, sustainable, person-centered community-based care system.

\section{Acknowledgements}

A portion of this manuscript was accepted as a virtual poster presentation at the Sigma Theta Tau International $46^{\text {th }}$ Biennial Convention, Indianapolis, USA (6-10 November 2021). This work was supported by JSPS KAKENHI Grant Number JP20K11007.

\section{Conflicts of Interest}

The author declares no conflicts of interest regarding this paper.

\section{References}

[1] Glanville, J., Kendrick, T., McNally, R., Campbell, J. and Hobbs, R. (2011) Research Output on Primary Care in Australlia, Canada, Germany, the Netherlands, the United Kingdom, and the United States: Bibliometric Analysis. BMJ, 342, d1028. https://doi.org/10.1136/bmj.d1028

[2] Imaiso, J. (2018) Outcomes of Integrated Community Care Interventions for Frail Elderly People: A Literature Review. Health, 10, 1120-1131. https://doi.org/10.4236/health.2018.108085

[3] World Health Organization (n.d.) The Determinants of Health. https://www.who.int/health-topics/social-determinants-of-health\#tab=tab 1

[4] Phillips, J., Richard, A., Mayer, K.M., Shilkaitis, M., Fogg, L.F. and Vondracek, H. (2020) Integrating the Social Determinants of Health into Nursing Practice: Nurses' Perspectives. Journal of Nursing Scholarship, 52, 497-505. https://doi.org/10.1111/jnu.12584

[5] Gaugler, J.E. (2015) Aging of Communities: Communities of Aging. Journal of Applied Gerontology, 34, 135-137. https://doi.org/10.1177/0733464814562271

[6] Wen, M., Cagney, K.A. and Christakis, N.A. (2005) Effect of Specific Aspects of Community Social Environment on the Mortality of Individuals Diagnosed with Serious Illness. Social Science \& Medicine, 61, 1119-1134. 
https://doi.org/10.1016/j.socscimed.2005.01.026

[7] Imaiso, J. (2015) Negative/Positive Home-Based Caregiving Appraisals by Informal Carers of the Elderly in Japan. Primary Health Care Research \& Development, 16, 167-178. https://doi.org/10.1017/S1463423614000309

[8] Mainous, A.G. and Kohrs, F.P. (1995) A Comparison of Health Status between Rural and Urban Adults. Journal of Community Health, 20, 423-431.

https://doi.org/10.1007/BF02260438

[9] Chiu, H.H., Chen, C.M., Huang, C.J. and Mau, L.W. (2005) Depressive Symptoms, Chronic Medical Conditions and Functional Status: A Comparison of Urban and Rural Elders in Taiwan. International Journal of Geriatric Psychiatry, 20, 635-644. https://doi.org/10.1002/gps.1292

[10] Friedman, B., Conwell, Y. and Delavan, R.I. (2007) Correlates of Late-Life Major Depression: A Comparison of Urban and Rural Primary Care Patients. The American Journal of Geriatric Psychiatry, 15, 28-41. https://doi.org/10.1097/01.JGP.0000224732.74767.ad

[11] Apidechkul, T. (2011) Comparison of Quality of Life and Mental Health among Elderly People in Rural and Suburban Areas, Thailand. Southeast Asian Journal of Tropical Medicine and Public Health, 42, 1282-1292.

[12] Fonseca, X., Lukoscha, S. and Brazier, F. (2019) Social Cohesion Revisited: A New Definition and How to Characterize It. The European Journal of Social Science Research, 32, 231-253. https://doi.org/10.1080/13511610.2018.1497480

[13] Imaiso, J. (2020) Considerations of Social Aspects and Mental Health for Community-Dwelling Elderly People. Health, 12, 486-498. https://doi.org/10.4236/health.2020.125038

[14] Schroeder, S.A. (2007) We Can Do Better-Improving the Health of the American People. The New England Journal of Medicine, 20, 1221-1228.

https://doi.org/10.1056/NEJMsa073350 